\title{
PESQUISA (AUTO)BIOGRÁFICA, CULTURA E COTIDIANO ESCOLAR: DIÁLOGOS TEÓRICO-METODOLÓGICOS
}

\author{
Elizeu Clementino de Souza ${ }^{\mathrm{i}}$ \\ Universidade do Estado da Bahia \\ esclementino@uol.com.br \\ Rita de Cássia Magalhães de Oliveira ${ }^{\mathrm{ii}}$ \\ Universidade do Estado da Bahia \\ rcmagal@yahoo.com.br
}

\begin{abstract}
Resumo
$\mathrm{O}$ texto sistematiza questões teórico-metodológicas sobre pesquisa (auto)biográfica e suas relações com as práticas cotidianas construídas numa escola rural da comunidade ruralquilombola no distrito de Matinha dos Pretos em Feira de Santana-Ba, configurando-se como entrada de um subprojeto da pesquisa 'Diversas ruralidades - Ruralidades diversas: sujeitos, instituições e práticas pedagógicas', financiada pela Fapesb e CNPq. Objetiva analisar modos como as culturas desta comunidade são reconstruídas nas práticas cotidianas da escola, através da utilização de entrevistas narrativas, grupo de discussão e registros no diário de campo, como dispositivos férteis para a apreensão da cultural local e suas interfaces com o cotidiano escolar.
\end{abstract}

Palavras-chave: Pesquisa (Auto)biográfica; Narrativas de vida; Cotidiano escolar; Comunidade rural-quilombola.

\section{(AUTO)BIOGRAPHICAL RESEARCH, CULTURE AND SCHOLAR EVERYDAY LIFE: theoretical and methodological dialogues}

\begin{abstract}
This text addresses theoretical and methodological issues of (auto)biographical research and its relationship to everyday practices built in a rural school rural-quilombola community in the Matinha dos Pretos district in Feira de Santana, Bahia. It is configured as part of a subproject research 'Diversas ruralidades - Ruralidades diversas: sujeitos, instituições e práticas pedagógicas', project funded by Fapesb and CNPq. It aims to analyze ways in which the cultures of this community are rebuilt in everyday practices in school, through the use of narrative interviews, group discussion and records in research diary (field notes), as fertile devices for the understanding of the local culture and its interfaces with scholar everyday life.
\end{abstract}

Keywords: (Auto)biographical research; Llife narratives; Scholar everyday life; Ruralquilombola community.

\section{PESQUISA (AUTO)BIOGRÁFICA, CULTURA E COTIDIANO ESCOLAR: DIÁLOGOS TEÓRICO-METODOLÓGICOS}

Catar feijão se limita com escrever: joga-se os grãos na água do alguidar e as palavras na folha de papel; e depois, joga-se fora o que boiar. 
Certo, toda palavra boiará no papel, água congelada, por chumbo seu verbo: pois para catar esse feijão, soprar nele, e jogar fora o leve e oco, palha e eco.

Ora, nesse catar feijão entra um risco: o de que entre os grãos pesados entre um grão qualquer, pedra ou indigesto, um grão imastigável, de quebrar dente.

Certo não, quando ao catar palavras: a pedra dá à frase seu grão mais vivo: obstrui a leitura fluviante, flutual, açula a atenção, isca-a como o risco. (MELO NETO, 2002, p. 23)

Como as palavras têm magia, vamos nos apropriar da metáfora de Melo Neto (1996), para criar outra metáfora (se é que a estrutura da língua permite), que neste momento possibilita pensar na relação entre "catar feijão", pesquisar e escrever. Então, pediremos autorização ao autor e à estrutura da língua para comparar o catar feijão com a ação de pesquisar e os desafios teórico-metodológicos que se colocam no processo de pesquisar, numa perspectiva colaborativa.

Ao comparar o catar feijão com o ato de escrever, o poeta nos diz que esse processo passa pela escolha. Catar e escrever são atos muito próximos, mas não são iguais, na medida em que ocorrem no fazer cotidiano de quem cozinha feijão (e pretende que só tenha feijão) e de quem escreve (e quer evitar um som desagradável). Assim, o ato de pesquisar no/do/com o cotidiano escolar, pode ser também comparado com o catar feijão, portanto, é sempre um ato de escolha.

Catar, escolher e escrever passam pelas nossas escolhas e pelas formas como nos colocamos diante da vida e do mundo. Nossa opção teórico-metodológica implica aprender a não “jogar fora” o que for “oco, palha e eco”, sem, contudo, considerar o que poderá ficar de fora como desperdícios. Nessa escolha, reafirmamos diálogos fecundos com questões epistemológicas e teórico-metodológicas da pesquisa (auto)biográfica, apreendendo os sujeitos como instituintes e constituintes de suas ações pessoais e sociais. Assim, entendemos que pesquisar implica demarcar, com certa clareza, o objeto a ser estudado e os caminhos escolhidos por quem pesquisa, o que não nos impede de correr riscos e estarmos atentos para superarmos receitas e modelos que ignoram as histórias de vida dos sujeitos, seus saberes e suas práticas cotidianas, especialmente, no que se refere aos modos como cada um vive e constrói suas experiências culturais numa comunidade rural-quilombola e no contexto escolar.

O rigor da escolha pode ser feito de várias maneiras, mas cada sujeito que vai pesquisar catar feijão, precisa compreender o que está sendo pesquisado, para evitar ou diminuir os riscos de encontrar "um grão qualquer, pedra ou indigesto, um grão imastigável" nas suas escolhas 
de/na pesquisa. Para Macedo, compreender é uma tarefa crucial no processo de pesquisa. Neste sentido, afirma o autor que:

Compreender compreensões é uma das tarefas árduas do pesquisador das qualidades humanas. Diria mesmo, é a sua atividade predominante num processo de pesquisa qualitativa. Mas um dos nossos desafios mais cruciais é compreender a compreensão. Nestes termos, tratar com sentidos na sua complexidade, tarefa fundante das pesquisas qualitativas, implica em ampliar a compreensão do que seja compreensão, com várias consequências importantes para a pesquisa de base qualitativa e suas variantes. É preciso realçar que compreender já é uma atividade inerente à própria existência, como tal, é a ação, e, por consequência, é do âmbito da alteração, da concretude do Ser. (MACEDO, 2009, p. 87)

Quando se inscreve na abordagem qualitativa, a pesquisa exige o rigor da compreensão, mas isto não significa rigidez e inflexibilidade, ao contrário, ao imergirmos no universo dos sujeitos sociais, precisamos ampliar nossos sentidos numa tarefa hermenêutica e perceber também o que os outros sentidos e gestos nos apontam. Como afirma Galeffi: “[...]. Rigor e flexibilidade andam juntos na pesquisa qualitativa, porque o excesso de rigidez deve ser corrigido ou equilibrado com a flexibilidade, assim como o excesso de flexibilidade tem que ser corrigido com o tensionamento justo [...]" (2009, p. 38).

Desta forma, compreender exige de quem pesquisa o equilíbrio necessário para uma tarefa infinita que é a busca constante da compreensão. É a possibilidade de trazer o seu "grão mais vivo", "catar as palavras" nas narrativas, nos gestos, olhares, táticas, práticas da/na vida cotidiana.

Essa procura da/na vida cotidiana, nos impulsiona a estar lá constantemente pensando, refletindo e compreendendo. Na pesquisa pela compreensão na/da vida cotidiana na/da educação: "Entendendo como fundamental 'ir-se' à vida cotidiana, ao que acontece e ao que vivem as pessoas, para ser possível pensar a educação e seu potencial emancipatório, [...]" (OLIVEIRA 2008. p. 163). Desta maneira, é no cotidiano do campo empírico que o objeto da pesquisa tem seu "alguidar" ou sua "folha de papel" para ser investigado, catado e escrito.

Com o objetivo de sistematizar questões teórico-metodológicas sobre pesquisa (auto)biográfica, culturas e cotidiano escolar, o texto toma como referência experiências desenvolvidas na pesquisa Diversas ruralidades - Ruralidades diversas: sujeitos, instituições e práticas pedagógica em escolas rurais da Bahia-Brasil, coordenada pelo Grupo de Pesquisa (auto)biografia, Formação e História Oral, da Universidade do Estado da Bahia (GRAFHO/UNEB), financiada pela Fundação de Amparo à Pesquisa do Estado da Bahia (FAPESB) e pelo Conselho Nacional de Desenvolvimento Científico e Tecnológico (CNPq). As 
análises aqui empreendidas desdobram-se de um subprojeto de pesquisa realizado na comunidade rural-quilombola no distrito de Matinha dos Pretos em Feira de Santana-Ba, no que se refere às discussões sobre cultura, cotidiano escolar e prática pedagógica. Desta forma, buscamos sistematizar questões epistemológicas e teórico-metodológicas da pesquisa (auto)biográfica e suas relações com estudos do cotidiano escolar, demarcando nossas opções pelos dispositivos utilizados na pesquisa - entrevistas narrativas, grupo de discussão e diário de campo, bem como a apresentação, de forma abreviada, dos procedimentos de análise que realizamos no processo da pesquisa. Por fim, apresentamos alguns apontamentos conclusivos, no que se refere ao processo de catar palavras e significá-las, numa perspectiva colaborativa, através das experiências cotidianas vividas pelos sujeitos no ato de catar feijão e de enunciar as palavras, num texto narrativo e implicado sobre o processo da pesquisa.

\section{Uma metodologia, sua história, uma escolha: catar feijão e debulhar palavras}

"Ir-se" à vida cotidiana numa perspectiva heurística requer uma metodologia de observação, coleta de informações, escutas, escritas, verbalizações, silêncios, além de outras ações que se entrecruzam na vida cotidiana e no processo de pesquisar-viver. A escolha da metodologia passa por inúmeros fatores como, por exemplo, aderência/coerência com o objeto pesquisado, seu valor heurístico, a aplicação e o desenvolvimento em outras pesquisas, assim como outros fatores que influenciam direta ou indiretamente nos caminhos percorridos.

A escolha pela abordagem de cunho biográfico e (auto)biográfico como metodologia de pesquisa não está alheia a esses fatores, tudo se imbrica, as dúvidas não deixam de existir, assim como os riscos que qualquer metodologia pode apontar, contudo, a possibilidade multidisciplinar que a metodologia oferece, é sem sombra de dúvida um fator essencial para sua escolha.

Antes de adentrarmos em questões mais relacionais entre o objeto de pesquisa e a metodologia escolhida, faz-se necessário situarmos, breves apontamentos históricos e teóricometodológicos, características da pesquisa (auto)biográfica.

Biografar-se e ao outro não é uma prerrogativa dos sujeitos da modernidade e modernidade tardia. Pineau e Le Grand (2012) afirmam que a escrita com o nome bios, que é uma alusão às histórias de vida escritas, eram realizadas desde o século $\mathrm{V}$ antes de Cristo, embora só no século $\mathrm{V}$ depois de Cristo encontramos o termo biografia. Contudo, o termo autobiografia apareceu na Alemanha e Inglaterra por volta do início do século XIX.

Desta forma, é possível imaginar que mesmo sem o aparecimento dos termos: bios, biografia, autobiografia, os sujeitos sociais oralizavam, desenhavam, esculpiam suas vivências e

Revista Interinstitucional Artes de Educar. Rio de Janeiro, V. 2 N. Especial - pag 182-203 (jun - out 2016): "Vozes da Educação" 
experiências individuais e coletivas. Segundo Arfuch (2010), biografias, autobiografias, confissões, memórias, diários íntimos, correspondências dão conta, há pouco mais de dois séculos, de um movimento mais forte, na tentativa de deixar impressão, rastros, inscrições, com ênfase nas identidades e singularidades da vida, que ao mesmo tempo, constitui-se como busca de transcendência.

$\mathrm{Na}$ modernidade, mais precisamente no final do século XIX na Alemanha, aparece o método biográfico na perspectiva metodológica (FINGER, 2010 e NÓVOA, 2010). No início do século XX entre os anos de 1920 e 1930, os sociólogos norte-americanos da Escola de Chicago utilizaram o método biográfico como instrumento de pesquisa, indo de encontro a uma sociologia positivista que não permitia que seus estudantes entrassem em contato com o mundo real. Inaugurava-se a era em que a sociologia partia para a observação de campo, coleta de dados, aproximando-se do objeto pesquisado. De acordo com Batista Neto, os sociólogos da Escola de Chicago “[...], sobretudo os das duas primeiras gerações, foram os primeiros a reconhecer o valor epistemológico e metodológico dos relatos de vida, sendo responsável por seu uso sistemático" (2007, p. 4).

É inegável a influência que a Escola de Chicago teve para que a Abordagem Biográfica (FERRAROTTI, 2010), (FINGER, 2010 e NÓVOA, 2010), (PINEAU e LE GRAND, 2012), (MONTEAGUDO, 2011), (SOUZA, 2006), (BATISTA NETO, 2007) fosse utilizada como metodologia de pesquisa. Tal influência ancora-se na Sociologia contemporânea e, posteriormente, na História, Etnografia, Psicologia/Psicanálise, Literatura, Linguística e na Educação (PENEAU, 2012 e LE GRAND, 2012).

A tradição da Sociologia de Chicago foi decisiva para o uso de determinados recursos nas pesquisas de abordagem biográfica como, por exemplo: “[...] a observação em in situ, às vezes com participação (pesquisa participante), histórias de vida, análise de documentos oficiais e pessoais, narrativas e entrevista" (MACEDO, 2007 p. 61). Para Ferrarotti (2010), desde seu aparecimento nos estudos da Escola de Chicago como metodologia de investigação científica, o método biográfico, passou por metamorfoses e foi a sociologia que utilizou pela primeira vez, muitas vezes, implicando em rupturas com ditames positivistas e proposições epistemológicas centradas nas histórias, cotidianos, narrativas e experiências migratórias vividas pelos sujeitos na sociedade americana dos anos 20 do século passado. Ainda assim, ao fazer críticas à sociologia pelo uso do método biográfico, Ferrarotti afirma que:

Subjetivo, qualitativo, alheio a todo o esquema hipótese-verificação, o método biográfico projeta-se à partida fora do quadro epistemológico estabelecido das

Revista Interinstitucional Artes de Educar. Rio de Janeiro, V. 2 N. Especial - pag 182-203 (jun - out 2016): "Vozes da Educação" 
ciências sociais. A sociologia não aceitou o desafio que lhe era lançado por essa diversidade epistemológica e fez de tudo para reduzir o método biográfico para o interior do quadro tradicional. E a que preço! Por meio de um duplo desvio epistemológico e metodológico, procurou-se utilizar o método biográfico, anulando completamente a sua especificidade heurística. (2010, p. 37)

A crítica feita por Ferrarotti (2010) à sociologia, por uma das formas como se apropriou do uso do método biográfico, serve de alerta para nós pesquisadores, quando escolhermos esta perspectiva metodológica na pesquisa. Assim, todo e qualquer processo de hipótese/verificação (entre outras questões) nos coloca de volta nos moldes das pesquisas positivistas em busca de uma objetividade e nos distancia de perceber aquilo que a subjetividade pode nos apontar num tempo e espaço próprio. Assim, "Um símbolo vivo pode surgir durante a pesquisa. Ele apresenta-se como mistério a ser decifrado, aparece como uma tensão criativa e transformadora que, ao lançar o pesquisador no espaço do desconhecido, possibilita desencadear processos de descoberta e conhecimento" (FURLANETTO, 2008, p. 96).

Ao pensarmos nessas descobertas que não estão nos scripts das hipóteses, um número significativo de ciências vem utilizando a abordagem biográfica como metodologia de investigação, mas essa metodologia apresenta uma diversificação terminológica, caracterizada pelos diversos tipos e práticas de investigação (SOUZA, 2006). A análise construída pelo autor sobre diferentes tipificações, através das diferenciações propostas por Pineau (1999), leva-nos a afirmar que "[...] o quadro apresentado pelo autor, marca uma análise de diferentes trabalhos desenvolvidos desde o final dos anos de 1980, com a abordagem biográfica. [...]" (SOUZA, 2006, p. 25). Ao fazer a análise desse quadro, Souza afirma que:

A diferenciação apresentada pelo autor, a partir do exame realizado sobre as produções na área, evidencia quatro categorias: "a biografia, a autobiografia, os relatos orais, e as histórias de vida": Dessa classificação apreendo os seguintes conceitos: a "biografia" "como escrita da vida do outro" (PINEAU, 1999, p. 343) inscreve-se numa abordagem denominada como abordagem biográfica; Pierre Dominicé (1996) define como "biografia educativa," por fazer entrada na trajetória educativa dos sujeitos; Christine Josso (1991) reconhece como "biografia formativa," pressupondo que o sujeito não pode entender o sentido da autoformação se não perceber as lógicas de apropriação e transmissão de saberes que viveu ao longo da vida, através de suas aprendizagens pela experiência. (SOUZA, 2006, p. 25)

Além das diferentes tipologias que foram apreendidas por Souza (2006), cabe ainda falar sobre a autobiografia que é um processo de escrita da própria vida; os relatos orais é o que se faz oralmente tanto da vida do indivíduo como da vida de uma coletividade, este tipo encontra 
seu lastro epistemológico na História Oral; e a história de vida, que muito se aproxima da tipologia da autobiografia. Ainda é possível acrescentar na perspectiva da abordagem biográfica as narrativas de vida, que segundo Bertaux (2010), “[...] foram introduzidas na França nos anos de 1950 com as Ciências Sociais. A narrativa de vida resulta de uma forma particular de entrevista, a entrevista narrativa, durante a qual um pesquisador (que pode ser um estudante) pede a uma pessoa, então denominada sujeito, que lhe conte toda ou parte de sua experiência vivida" (BERTAUX, 2010, p. 15).

Tanto as tipologias apresentadas por Souza (2006), quanto as que foram colocadas como complementação, serão pertinentes para entendermos as escolhas por uma abordagem biográfica. Os caminhos escolhidos para as trajetórias metodológicas são muitos, mas devem se aproximar do objeto pesquisado. [...] "o objeto da pesquisa biográfica é o de explorar os processos de gênese e de vir-a-ser dos indivíduos num espaço social, mostrar como eles dão forma a sua experiência, como fazem significar as situações e os acontecimentos de sua existência". (DELORY-MOMBERGER, 2012, p. 71).

A abordagem biográfica tem se revelado como excelente metodologia para ampliar as discussões na esfera das ciências da educação, que têm desenvolvido nas últimas décadas aprendizagens significativas e formativas em tempos distintos dos/nos ambientes educacionais formais e para além deles.

Além dos fatores citados acima, é preciso estarmos atentos enquanto pesquisadores, que a escolha da metodologia se vincula aos objetivos da pesquisa, ou seja, o que se objetiva pesquisar precisa ser pensado na escolha do caminho metodológico. No que se refere à utilização de uma metodologia:

[...]. Tem-se de levar em conta que na pesquisa qualitativa, principalmente nas modalidades biográficas os sujeitos colaboradores ocupam o primeiro plano da pesquisa na busca da compreensão da relação entre contexto social e percepções da cotidianidade. Invariavelmente, o que se busca compreender são os sentidos construídos em que se revelam representações ideológicas, símbolos e mitos sobre determinados aspectos da vivência humana e como essas representações podem ser re-significadoras. (CUNHA, 2012, p. 105)

Sendo o sujeito colaborador aquele que ocupa o primeiro lugar, suas narrativas, gestos, olhares precisam ser considerados, não apenas no momento do relato oral, mas nos diversos momentos da pesquisa. É preciso que a relação estabelecida não seja hierarquizada, mas sim colaborativa. Ouvir a narrativa do outro e pensar que o narrador pode ir além do que estava no 
script, é essencial, principalmente quando o pesquisador não vivencia o cotidiano, os saberes e as práticas do colaborador.

Ir-se em busca da palavra do outro é colocar-se à prova das múltiplas formas de estar no mundo, as quais são construídas pelas nossas andanças e pelos modos como os sujeitos vivem e narram a vida, como uma disposição do catar feijão e do contar suas histórias, através de suas experiências de vida cotidiana na comunidade e na escola. Essa é uma tarefa de quem se lança numa pesquisa de abordagem qualitativa, ao buscar a compreensão desse mundo da vida que se presentifica no cotidiano de uma escola.

Após apresentarmos, de forma abreviada, algumas questões sobre a constituição da pesquisa (auto)biográfica, buscaremos situar aspectos sobre as entrevistas narrativas, grupo de discussão e utilização do diário de campo, como dispositivos utilizados na pesquisa.

\section{Entrevistas narrativas na pesquisa de cunho biográfico e (auto)biográfico}

A entrevista narrativa se constitui na pesquisa biográfica e (auto)biográfica como um dispositivo de grande relevância no processo de investigação, principalmente quando voltada para as apropriações e apreensões das práticas cotidianas no campo educacional - escola.

Este dispositivo de pesquisa possibilita aprofundar determinadas questões que emergem nas narrativas dos sujeitos, quando suas histórias de vida se entrecruzam com os contextos sociais, culturais, econômicos, políticos e religiosos e, para além deles, de uma coletividade.

É no momento da entrevista narrativa, que entrevistador e entrevistado podem estabelecer uma relação dialógica de troca não só das informações narradas, mas dos gestos, dos olhares, dos movimentos do corpo que resultam nas entrelinhas do narrado. Para Benjamin (2012) a narrativa “[...] não se esgota jamais. Ela conserva suas forças e depois de muito tempo, ainda é capaz de desdobramentos. [...]”. (2012, p. 220). O dispositivo da entrevista narrativa, quando bem observado, planejado e executado nos possibilita, enquanto pesquisadores, a guardar por muito tempo os desdobramentos da entrevista narrativa.

Para Jovchelovich e Bauer (2002) a entrevista narrativa tem diversas fases que, se bem observadas e seguidas pelo entrevistador, possibilitam a inserção no mundo do entrevistado, naquilo que a memória dele/dela selecionou para contar. As principais fases (JOVCHELOVICH e BAUER 2002) de uma entrevista narrativa são: preparação, iniciação, narração central, perguntas, conclusão.

$\mathrm{Na}$ fase da exploração, o entrevistador reconhece o campo da pesquisa, explorando o máximo possível o processo de observação, para depois, formular as perguntas ou os principais 
eixos da entrevista. Na iniciação, escolher previamente o local da entrevista, marcar data e local com o entrevistado, escolher e separar os instrumentos de coleta de sons e imagens, fazer testes de aplicabilidade desses instrumentos são fundamentais para superação de possíveis questões técnicas. Durante a narração central - entrevista narrativa, observar o funcionamento dos instrumentos de áudio e imagens (se forem utilizadas), perceber outros ruídos do/no local, tentar ao máximo não interromper a narração, encorajar de forma não verbal o colaborador no seu processo narrativo, aguardar a finalização da narrativa. $\mathrm{Na}$ fase das perguntas que acontece concomitantemente com a narração central (às vezes, pode ir além), o entrevistador deve evitar emitir opiniões e ou fazer perguntas acerca das atitudes do entrevistado, evitar as perguntas por $q u e ̂$ ?. É na fase da conclusão, já com os instrumentos de coleta de sons e imagens deligados, que o entrevistador pode fazer perguntas com porquê? Fazer anotações que são essências para os registros das lembranças e detalhes da entrevista.

Embora a entrevista narrativa seja utilizada em diversas pesquisas nas mais diferentes ciências, apenas sugerimos esse possível roteiro, isto não significa o engessamento do dispositivo, os cuidados aqui apresentados, são apenas sinalizações de práticas já realizadas. Todavia, cada entrevistador/pesquisador, adequa as técnicas da entrevista narrativa ao objeto, objetivo, entrevistado e situação.

Desta forma, as entrevistas narrativas permitem a compreensão das “[...] alternâncias e cumplicidades, as homologias de procedimentos e as imbricações sociais que ligam às 'artes de dizer' às 'artes de fazer' [...]”' (CERTEAU, 2012, p. 141-142).

Ainda com Jovchelovitch e Bauer (2002), a entrevista narrativa consiste numa entrevista com perguntas abertas que encoraja o entrevistado a falar, a contar histórias. Neste caminho ela/ele nos diz:

As entrevistas narrativas são infinitas em sua variedade, e nós as encontramos em todo lugar. Parece existir em todas as formas de vida humana uma necessidade de contar; contar histórias é uma forma elementar de comunicação humana e, independentemente do desempenho da linguagem estratificada, é uma capacidade universal. (JOVCHELOVITCH e BAUER, 2002, p. 91)

A entrevista narrativa nos conecta enquanto pesquisadores, com as possibilidades de contar história dos/nos cotidianos dos sujeitos sociais, no ir e vir que se funda na necessidade de comunicação da vida. No entanto, os eixos ou perguntas utilizadas/estruturadas devem estar de acordo com as especificidades de cada grupo ou sujeito participante/colaborador, articulando-os com o objeto, os objetivos e as questões da pesquisa. 


\section{Grupo de Discussão: uma experiência coletiva com narrativas}

Cada palavra catada no alguidar das vidas revela a multiplicidade nos/dos sujeitos que vivem a ambivalência de lugares. As narrativas propiciadas no contexto de um grupo de discussão configuram-se como uma ação colaborativa, através da partilha de experiências de vida-formação. Os sujeitos (com)partilham os tempoespaços de suas vidas, na comunidade e na escola. Para Delory-Momberger, "O modo como os alunos vivem, representam e significam a escola e o que fazem ali não podem deixar de corresponder, sob ângulos e formas diversas, ao modo como eles próprios 'se narram' e o que eles narram sobre si mesmos. [...]" (DELORYMOMBERGER, 2008, p. 114). Esse modo como os(as) alunos(as) se narram acontece não só no espaço da escola, mas também nas suas vivências na comunidade. No grupo de discussão, a escuta da narrativa de si foi transformada numa narrativa e escuta coletiva, sem pensarmos que essa escuta coletiva seja a somatória de opiniões individuais, mas sim a expressão de experiências individuais e coletivas vividas contidamente pelos sujeitos.

O grupo de discussão tem algumas aproximações com o grupo focal. No entanto, sua configuração e história o coloca em uma posição de distinção e autonomia, tanto quando se constitui como processo metodológico, como dispositivo ou instrumento de coleta/recolha de informações.

Para Weller (2011), o Grupo Focal é constituído de um número de seis a oito pessoas e assemelham-se a um talk show. Os assuntos debatidos nesta técnica de entrevista têm características de debate aberto acessível a todos os participantes. Neste tipo de técnica ou instrumento de coleta de informações, o coordenador ou moderador tem uma participação bastante ativa no que diz respeito aos debates, ou seja, ele/ela participa dando opiniões e incentivando os participantes a emitirem as suas. É uma técnica de origem anglo-saxônica (Weller, 2011), e foi/é bastante utilizada como comunicação em marketing. Já o Grupo de Discussão se difere do GF nas questões do papel do pesquisador/moderador e nos objetivos a serem alcançados. Enquanto no GF o moderador tem posição de facilitador ativo na discussão, emitindo opiniões e intervindo amplamente nos processos de entrevista, no GD o pesquisador intervém o mínimo possível, seu papel é articular a discussão para obtenção da análise e compreensão do contexto dos participantes.

No Brasil, a utilização do grupo de discussão nas pesquisas educacionais ainda se faz de maneira muito tímida e restrita, sendo quantitativamente superado pelo Grupo Focal. De acordo com Weller (2011), os grupos de discussão foram utilizados inicialmente nas pesquisas sociais 
empíricas - Escola de Frankfurt - a partir da década de 1950 do século XX, mas o tratamento e procedimento que o tornaram um procedimento teórico-metodológico com base na etnometodologia, no interacionismo simbólico e na fenomenologia, só ocorreu na última metade da década de 1970 do mesmo século. Após esse tratamento metodológico, os grupos de discussão passam nos anos de 1980 a serem como utilizados como método/técnica de pesquisa.

No movimento do grupo de discussão, a postura funcional ou sociogenética do pesquisador deve levá-lo a interferir o mínimo nas discussões (WELLER, 2011), não se trata de ser uma figura decorativa e neutra, mas participante ativo, como um articulador que leve os participantes a refletirem sobre as narrativas das experiências, ou como essas narrativas revelam e (des)velam o contexto do mundo vida desses sujeitos. A posição do pesquisador é a aposta de escutar a partilha das experiências dos sujeitos.

Essa aposta nas narrativas coletivas marca um lugar de possibilidades nas revelações que se originam nos sujeitos que vivem as ambivalências sociais. O grupo de discussão permite ouvir alunos e alunas praticantes das vivências e experiências culturais no cotidiano da comunidade e das práticas da escola inundadas de práticas culturais. Desta forma, Weller afirma que:

Os grupos de discussão realizados com pessoas que partilham de experiências em comum reproduzem estruturas sociais ou processos comunicativos nos quais é possível identificar um determinado modelo de comunicação. Esse modelo não é casual ou emergente, muito pelo contrário: ele documenta experiências coletivas assim como características sociais desse grupo, entre outras: as representações de gênero, de classe social, de pertencimento étnico e geracional. Nesse sentido, os grupos de discussão, como método de pesquisa, constituem uma ferramenta importante para a reconstrução dos contextos sociais e dos modelos que orientam as ações do sujeito. (WELLER, 2011, p. 58)

No diálogo com Weller sobre o grupo de discussão, vamos percebendo que a escolha permite a (re)construção do contexto da comunidade e da escola, no que se refere às características sociais de representações de gênero, de classe social, de pertencimento étnico e geracional, etc., protagonizadas por sujeitos de múltiplos lugares e espaçotempos.

O trabalho com o grupo de discussão como método, dispositivo de coleta ou recolha de informações, permite ao pesquisador diversas possibilidades de olhares, inserções e percepções no/do universo da pesquisa. "Portanto, os grupos de discussão representam um instrumento através do qual, o pesquisador estabelece uma via de acesso que permite a reconstrução dos diferentes meios sociais e do habitus coletivo do grupo [...]” (WELLER, 2011, p. 58). Nesse trabalho, faz-se necessário rigor e flexibilidade para avaliar e empregar critérios de seleção, quantidade de participantes, tópico guia, organização e condução dos grupos (WELLER, 2011).

Revista Interinstitucional Artes de Educar. Rio de Janeiro, V. 2 N. Especial - pag 182-203 (jun - out 2016): "Vozes da Educação" 


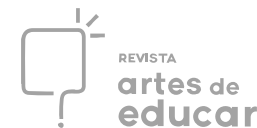

Ainda cabe esclarecer ou indicar que os grupos de discussão permitem um trabalho de pesquisa com múltiplos grupos com ou sem analogias/comparações e um caminho próprio de análise. No diálogo com Weller sobre o grupo de discussão, percebemos que a escolha possibilita a reconstrução do contexto da comunidade e da escola (características sociais de representações de gênero, de classe social, de pertencimento étnico e geracional, etc.), sujeitos de múltiplos lugares, sujeitos ambivalentes (posição tão comum nas discussões pós-modernas).

Essa aposta das narrativas coletivas ocorreu porque acreditamos nas possibilidades de revelações que se originam dos sujeitos que vivem essa ambivalência. Os participantes deste grupo foram inseridos nos seguintes critérios: (1) ser aluno ou aluna que estivesse cursando o $8^{\circ}$ e $9^{\circ}$ anos do Ensino Fundamental; (2) ter disponibilidade e vontade para participar de um grupo em que os trabalhos fossem desenvolvidos no contraturno das aulas regulares; (3) serem autorizados pelo pai, mãe ou outro responsável legal.

No trabalho de campo, entra o contexto de produção do grupo de discussão, composto por catorze alunos e alunas - treze adolescentes do sexo feminino e três do sexo masculino, com as seguintes idades: 02 com treze anos, 07 com catorze anos, 03 com quinze anos, 01 com dezesseis anos e 01 com dezessete anos. Os encontros foram realizados (grande parte das narrativas discursivas) em uma sala da escola rural, no turno oposto das aulas regulares, e no último encontro, nos dois turnos, no qual participamos de um almoço coletivo. Além desse espaço, utilizamos o pátio da escola, a praça da comunidade de Matinha dos Pretos, a igreja católica e outros espaços externos - sugeridos pelo grupo (todos os movimentos nos espaços foram autorizados previamente pelo pai, mãe ou responsável).

\section{Outro dispositivo de investigação: diário de campo}

No percurso de investigação do/no/com cotidiano ${ }^{\text {iii }}$, o diário de campo teve/tem como razão principal ser o lugar de registro dos movimentos das leituras de tempos e espaços, das observações que ocorrem/ocorreram “[...] no ambiente escolar: situações, diálogos, ambientes etc., tanto no que diz respeito ao espaço físico quanto à dinâmica da instituição e também as situações de interação entre os sujeitos [...]" (CAVALLEIRO, 2011, p. 275) enfim, do que na escola e na comunidade vimos, ouvimos e vivemos. É/foi este diário que virou documento em que a descrição se materializa/materializou. Segundo Macedo, o diário:

Além de ser utilizado como instrumento reflexivo para o pesquisador, o gênero diário é, em geral, utilizado como forma de conhecer o vivido dos atores pesquisados, quando a problemática da pesquisa aponta para a apreensão dos

Revista Interinstitucional Artes de Educar. Rio de Janeiro, V. 2 N. Especial - pag 182-203 (jun - out 2016): "Vozes da Educação" 
significados que os atores sociais dão à situação vivida. O diário é um dispositivo na investigação, pelo seu caráter subjetivo, intimista. (2007, p. 134)

Desta forma, a utilização do diário de campo configura-se como espaço/lugar das anotações das diversas itinerâncias no/do processo da pesquisa. Tanto nas entrevistas narrativas como no grupo de discussão, os sujeitos narraram o fazer da vida, na sua individualidade e coletividade. Para Pineau e Le Grand, "Fazer a vida, nunca foi fácil. Ganhá-la também não" (2012, p. 15). Assim, narrar a vida segue a mesma tendência de fazer e de ganhar. Narrar exige do narrador a possibilidade de brincar com o tempo. Ao narrar, evocamos a memória que nos traz as lembranças, entretanto o ato de lembrar se diferencia do ato de narrar. Quando lembramos os acontecimentos de nossa vida, através da memória, permitimos que as lembranças nos cheguem com os mais variados detalhes. Ao narrar o que a memória lembrou, selecionamos aquilo que queremos dizer, desvelamos e revelamos no discurso, apenas o que desejamos que o outro saiba, de forma sutil vamos permitindo o que para nós é possível.

Eis um grande e fascinante jogo com as nossas emoções! Somos os artífices da nossa história contada por nós, vamos tecendo fio a fio, até que o tecido revelado tenha os tons que aceitamos ou achamos que podemos aceitar. É o jogo constante entre a narrativa, a lembrança e o tempo. Esse jogo de tecer fio a fio da narrativa pode ser refletido a partir dos trabalhos científicos de pesquisadores do interacionismo simbólico.

Mesmo sem terem produzido biografias e utilizado autobiografias em seus processos de pesquisa, os pesquisadores do interacionismo simbólico nos deram uma significativa contribuição para entendermos a relação que se processa entre a narrativa de vida e o tempo linear. Nessa relação, uma narrativa não é o tempo do acontecimento, mas o recontar da memória sobre o acontecimento. É o tempo numa recomposição.

Sendo assim, recompor o tempo em uma narrativa demanda o esforço da busca da memória, evocado num tempo presente, pois ouvir uma história é partilhar a companhia do narrador (BENJAMIM 2012). Ao narrar uma história o narrador transmuta a linearidade imposta pelo tempo chronus, muitas vezes, presente e passado se misturam sutilmente (ou não), mas é a evocação da memória atual que busca as lembranças desse passado.

Em tempos de aceleração dos fluxos (informação, financeiro, transportes, pessoas, etc.) é cada vez mais paradoxal evocar a memória para narrar a vida, tendo a companhia de quem escuta. Ao mesmo tempo em que se vive a busca por uma padronização global dos comportamentos de consumo, se inscreve um crescente processo de individualização dos sujeitos, há uma dificuldade em partilhar histórias contadas. O contar a vida se processa como 
um paradoxo. Nesta perspectiva, Bauman nos diz: "as vidas vividas e as vidas contadas são, por essa razão, estreitamente interconectadas e interdependentes. [...] as histórias de vidas contadas interferem nas vidas vividas antes que as vidas tenham sido vividas para serem contadas [...]" (2008, p. 15).

Nesse paradoxo existente, é cada vez significativa a busca por esse narrar a vida, num ritmo multidisciplinar, que vai desde os consultórios médicos até os espaços virtuais, perpassando pelas ciências sociais e as ciências da educação - mas mesmo sendo de interesse de múltiplas ciências, este narrar a vida tem objetivos e trajetórias diferenciadas.

\section{Perspectiva de análise: alguns diálogos possíveis}

No processo de análise das entrevistas narrativas partimos das ideias apresentadas por Bertaux (2010), no que se refere à análise compreensiva, com bases na hermenêutica (GADARMER, 1996) e a sequência de codificação de Goss (2011), que tem como base principal a análise temática de Phillip Mayring, sistematizada por Jovchelovitch e Bauer (2002). Cabe também destacar as contribuições sobre análises interpretativas-compreensivas, conforme sistematizadas por Souza (2014), possibilitando-nos diálogos com as histórias, narrativas e experiências dos sujeitos sobre cultura e cotidiano na escola da comunidade rural-quilombola no distrito de Matinha dos Pretos em Feira de Santana-Ba.

As escolhas de tais fontes, acolhidas pelo fato de apresentarem possíveis aderências com o objeto da pesquisa, principalmente pela riqueza temática narrada pelos sujeitos participantes/colaboradores da pesquisa. Nesta perspectiva de análise, “[...] o texto é disposto em três colunas: na primeira é colocada a transcrição completa da entrevista, na segunda faz-se uma condensação, apontando os temas mais importantes e, na terceira, selecionam as palavras-chave" (GOSS, 2011, p. 225). Por fazermos a interação com a análise compreensiva de Bertaux (2010), acrescida de outras escolhas na pesquisa, fizemos uma (re)organização da matriz de análise das entrevistas narrativas, que foi apresentada da seguinte forma: Cabeçalho com as perguntas da pesquisa, seguido de objetivo geral. $\mathrm{Na}$ disposição das colunas colocamos: na primeira os objetivos específicos, na segunda a retranscrição ${ }^{\text {iv }}$, na terceira, quem é o sujeito/grupo que fala, na quarta faz-se uma condensação, apontando os temas mais importantes, na quinta selecionam as palavras-chave e na última a compreensão/leitura do(a) pesquisador(a).

\section{Matriz de Análise das Entrevistas Narrativas}

\begin{tabular}{|c|c|c|c|c|c|}
\hline $\begin{array}{c}\text { Objetivos } \\
\text { específicos }\end{array}$ & $\begin{array}{c}\text { Retranscrição } \\
\text { das entrevistas }\end{array}$ & Sujeito & Temáticas & Palavras-Chave & $\begin{array}{c}\text { Compreensão/ } \\
\text { leitura dos }\end{array}$ \\
\hline
\end{tabular}




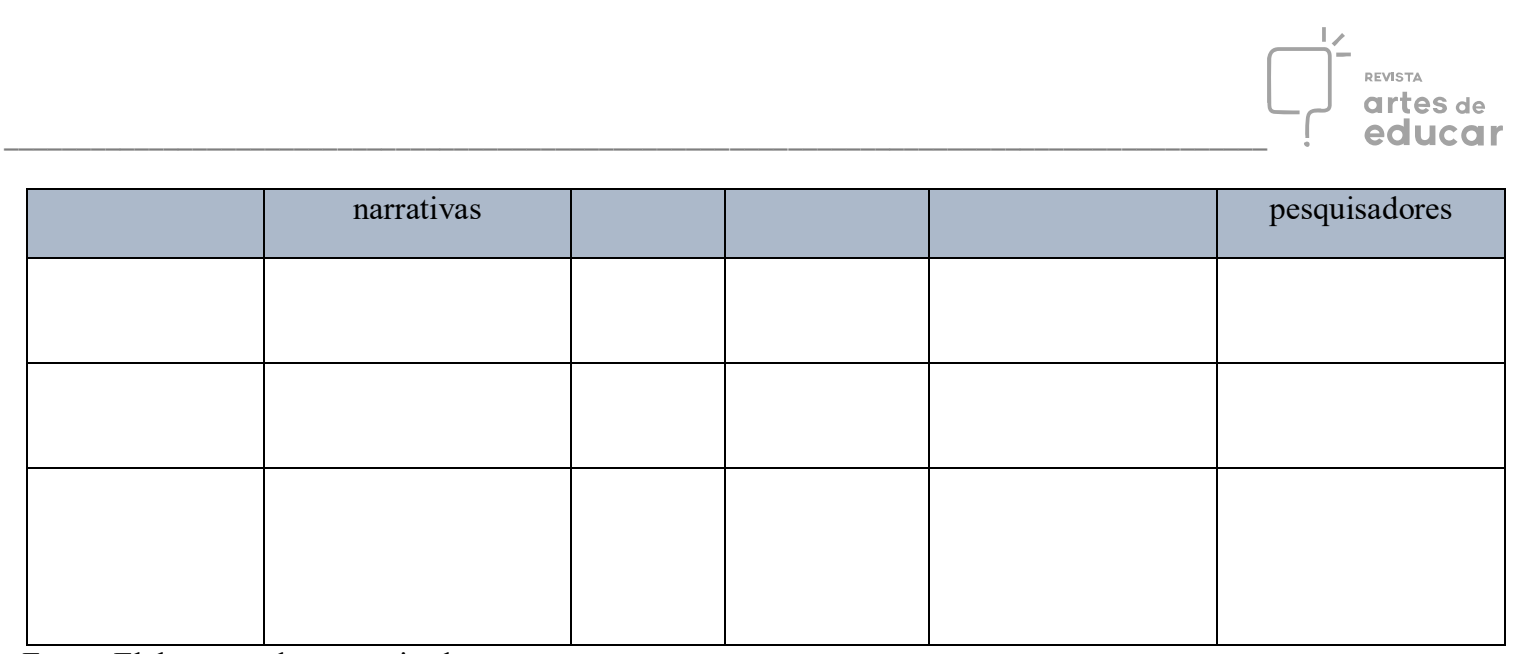

Fonte: Elaboração dos pesquisadores.

No processo da pesquisa entendemos também que o trabalho de produção das fontes e coleta de informações desenvolvidas nas entrevistas narrativas e no grupo de discussão narrativas dos alunos/alunas, implicam num primeiro encontro para a apresentação dos sujeitos, a explicação do objetivo do grupo e uma temática sobre juventude e lugar de moradia. No segundo encontro, foi exibido o filme ${ }^{\mathrm{v}}$ Os Croods (2013), o qual apresentava uma família da préhistória, que vivia a maior parte do seu tempo dentro de uma caverna, onde a liderança era exercida pelo pai - um homem que tinha muito medo do mundo além da caverna, mantendo, através do discurso, a família sob o escudo desse medo. Até que sua filha adolescente, que discordava daquela atitude, resolveu aventurar-se para além da caverna. Assim, nesta aventura, conheceu um jovem que lhe apresentou um mundo diferente do conhecido, fazendo com que toda a família que vivia na caverna, escondida dos perigos daquele mundo, fosse obrigada a viver a aventura de experimentar outros hábitos, outras práticas e outras culturas.

A escolha pela exibição deste filme não teve um caráter de análise, recepção e apropriação sociológica, mas sim a intenção de propormos possíveis deslocamentos e relações com as histórias que cada um vive em seu cotidiano. Como nos aponta Geimer: “[...], a análise qualitativa de filmes nas Ciências Sociais e na Educação não tem tradição particular” (2011, p. 135). São os Estudos Culturais que desenvolvem as principais linhas de pesquisa/análise de filmes e produções midiáticas.

Nossa intenção era utilizar o filme (ainda que com todas as críticas que podem advir do contexto, enredo, linguagem, produção, distribuidor, etc.) para articular a temática com um modo de recepção "[...] como experiência do mundo. Neste caso, os filmes não são unicamente integrados na prática cotidiana, mas a prática cotidiana exibida nos filmes é relacionada com a própria prática cotidiana [...]” (GEIMER, 2011, p. 141). Queríamos através do uso de uma estratégia lúdica relacionar, comparar e contrastar aquela prática cotidiana exibida no filme com a prática cultural cotidiana daqueles sujeitos. Esse material foi produzido em narrativas escritas 
em subgrupos de discussão. A análise do material produzido pelo grupo de discussão - filme foi ancorada na análise das narrativas escritas em que [...] "um filme aparece como recurso da experiência de mundo" (idem, p. 146).

Os demais encontros foram realizados com a produção de imagens da/na comunidade, feitas por alunos/as em máquinas fotográficas, câmera de celular e filmadora, alguns disponibilizados pelos pesquisadores, outros materiais dos próprios participantes (alunos e alunas) do grupo de discussão.

Em cada encontro eram sugeridas temáticas sobre a comunidade e os participantes produziam as imagens, a partir de seu ponto de vista sobre os aspectos da(s) cultura(s) do lugar. Tais imagens eram trazidas para a escola, projetadas numa tela e os(as) participantes faziam as imagensnarrativas do que era captado pelas lentes. As narrativas do grupo de discussão foram gravadas em áudio e vídeo e sua análise teve como base a análise apresentada por Bohnsack \& Weller (2011), baseada no próprio trabalho de interpretação de Bohnsack (1987 e 2007).

Para os pesquisadores uma análise interpretativa-compreensiva nunca pode ser realizada numa única etapa. Assim, sugerem etapas de análise que são: organização temática (fazer relatório de cada encontro com o grupo de discussão, anotar informações sobre o contexto para a realização do grupo, como realizou o contato com os(as) participantes; aplicar questionário sobre o perfil dos participantes do grupo para posteriores identificações das narrativas construídas na discussão; identificação dos temas surgidos durante os encontros, verificar o grau de envolvimento de cada participante e fazer a transcrição apenas das questões relacionadas ao objeto da pesquisa (nessa pesquisa, transcrevemos o material gravado integralmente). Depois dessa etapa, seguimos com a Interpretação Formulada que consistia em saber se a temática foi sugerida pelo pesquisador ou pelo grupo, aqui buscava-se descobrir o sentido das discussões - o que foi discutido, “[...] busca-se compreender o sentido imanente das discussões e decodificar o vocabulário coloquial” (BOHNSACK \& WELLER 2011, p. 81). Na etapa seguinte, fizemos a Interpretação Refletida que objetivava "a reconstrução do modelo de orientação coletiva, do habitus coletivo" (idem) - nisto procurava-se analisar o conteúdo da entrevista e as ações dos indivíduos, assim como o que está por trás dessas ações. Na última etapa de análise os pesquisadores sugerem a análise comparativa, mas como só trabalhamos com um grupo de discussão, não realizamos essa etapa.

\section{Matriz de Análise do Grupo de Discussão}




\begin{tabular}{|c|c|c|c|c|}
\hline $\begin{array}{c}\text { Objetivos } \\
\text { específicos }\end{array}$ & Organização temática & $\begin{array}{c}\text { Interpretação } \\
\text { formulada }\end{array}$ & $\begin{array}{c}\text { Interpretação } \\
\text { refletida }\end{array}$ & $\begin{array}{c}\text { Compreensão/ } \\
\text { leitura dos pesquisadores }\end{array}$ \\
\hline & & & & \\
\hline & & & & \\
\hline
\end{tabular}

Fonte: Elaboração dos pesquisadores.

Cabe destacar que a questão ética foi de extrema relevância, tanto pelo compromisso dos pesquisadores, quanto pela opção de submeter a pesquisa ao Comitê de Ética da Instituição (CEP/UNEB) que abriga a pesquisa. Os caminhos percorridos foram balizados pelos cuidados permanentes na explicação da pesquisa, seguida do convite, aceite do participante e da instituição onde seria desenvolvida a mesma, escolha do local das entrevistas e do grupo de discussão com consentimento dos participantes, e no caso dos alunos, menores de idade, houve a solicitação de consentimento do pai, mãe ou responsável. Além dessas questões, outras foram também essenciais como, por exemplo, autorização para gravação e publicação do material, seguindo os cuidados apresentados pelo comitê de ética.

Estes cuidados éticos estão explicitados nos documentos apresentados ao comitê de ética e aos participantes. Os mesmos foram: Termo de compromisso do pesquisador; Declaração de concordância com o desenvolvimento do projeto de pesquisa; Termo de confidencialidade; Termo de autorização institucional; Termo de autorização da instituição coparticipante (instituição vinculada/pesquisada); Termo de consentimento livre e esclarecido (elaborado de acordo com a linguagem e compreensão de cada grupo de participantes); Termo de assentimento. Todas essas questões éticas envolvem o(a) pesquisador(a) num contexto de responsabilidade com a narrativa do outro, os benefícios ou riscos que esse processo pode ocasionar. Nesta perspectiva SOUZA (2006), ao teorizar sobre essa questão, afirma que:

[...] a utilização e a publicização das identidades dos sujeitos envolvidos em processo de pesquisa e/ou de investigação-formação exige, do ponto de vista ético, uma aproximação e reaproximação das singularidades e subjetividades, bem como a adoção de alguns critérios: assinatura do termo de autorização (carta de cessão); explicitação dos procedimentos de análise e de como serão utilizadas as fontes na pesquisa; devolução e leitura do trabalho com o grupo e, consequentemente, revisão e autorização para utilização da narrativa. (2006, p. 
Desta forma, esses procedimentos nos levaram a adotar uma postura de proteger as identidades civis destes sujeitos, adotando nomes fictícios para a publicação parcial ou total das suas narrativas. Sabemos que é extremamente difícil o total sigilo - confidencialidade, pois manteremos o nome do local de pesquisa, das manifestações artísticas e religiosas, das atividades pedagógicas, assim como algumas particularidades da comunidade. Isto pode contribuir para a identificação de alguns sujeitos por parte das pessoas da própria comunidade e da escola.

A confidencialidade dos nomes civis ou apelidos, como são chamados pelos familiares e outros pares da comunidade dos colaboradores da pesquisa nos levou a pensar nas estratégias para equacionar a questão. Não poderíamos simplesmente colocar qualquer nome, era preciso pensar num batismo, numa outra identidade, para fazermos uma tessitura em que este universo fictício tivesse aproximações com a pesquisa. Foi preciso ouvir os sons das diversidades culturais que circulavam pela escola de uma comunidade rural, a fim de ouvirmos as formas como cada colaborador gostaria de ser nomeado na pesquisa, sempre respeitando suas histórias e suas experiências.

\section{Alguns apontamentos (in)conclusivos: outros diálogos possíveis}

Os caminhos da pesquisa nos levam para uma aventura que se refaz cotidianamente, tanto nos processos das entrevistas narrativas, como nos desenvolvidos no grupo de discussão e anotados detalhadamente no diário de campo. Todos estes movimentos formam os diversos momentos vividos para apreendermos relações entre as culturas de uma comunidade rural quilombola, seus sujeitos e as práticas vividas cotidianamente na escola. Para os sujeitos do lugar que estão vivendo apenas no espaço da comunidade, as narrativas marcam uma identidade/pertencimento a uma ancestralidade quilombola. Os sujeitos se autodeclaram negros, quilombolas e moradores da roça. Essa ancestralidade é marcada por uma prática do samba de roda, como elemento da identidade cultural. Os sujeitos narram que o samba de roda se constitui como um elemento marcante na sua vida e dizem: "Porque eu posso tá cansada como for, tem um samba de roda ali e eu vou.” (MI, entrevista narrativa - comunidade, 2013).

Para os jovens que vivem cotidianamente entre a comunidade e a escola, suas narrativas revelam modos como vivem com a agricultura, a fabricação de polpa de frutas e derivados da mandioca em pequenas cooperativas - trabalho liderado pelas mulheres; a festa do padroeiro, a 
festa junina com suas quadrilhas, o samba de roda, a etnicidade negra como produções culturais da Matinha dos Pretos.

Narram que o samba de roda é uma identidade do lugar, que o grupo Quixabeira da Matinha com apenas 20 anos de existência é considerado como a expressão maior da sua cultura. Este grupo de samba de roda é narrado com diferença entre a comunidade - os mais velhos, e a comunidade - os mais jovens. Para os mais velhos é o samba de roda por si só que representa a manifestação cultural. Para os mais jovens, o orgulhar-se do samba de roda vem acompanhado da existência da Quixabeira da Matinha. Aqui é preciso dizer que compreendemos que o aparecimento do grupo na mídia da cidade, do estado e nacional - acompanhado de figuras da música popular brasileira, tem contribuído para essa imagem do samba de roda produzida pelos mais jovens. No grupo de discussão também surgiu uma identificação com a categoria roça - são eles e elas que se dizem moradores da roça. Admitem que trabalham na lida da roça, capinando, limpando terreiro e fazendo tarefas de casa. Assim, nos mostram outra dimensão do trabalho para crianças e jovens que não está associado à exploração capitalista.

Alunos e alunas reconhecem sua ancestralidade quilombola - se declaram negros e negras e apontam que o preconceito invade a escola. Para eles e elas o comportamento de determinados(as) professores(as) mostra uma postura preconceituosa, ainda que de forma velada. Narram que as práticas escolares não contemplam as especificidades do rural e acreditam que se professores e professoras trabalhassem com práticas pedagógicas cotidianas que contemplassem essa dimensão do rural, eles e elas poderiam aprender na escola as possibilidades de permanecer no lugar.

Desta forma, a pesquisa nos aponta para uma reflexão mais aprofundada sobre os tensionamentos postos na relação que se estabelece entre as culturas de um lugar ruralquilombola e as práticas da escola. Faz-se necessário outros pensares, saberes e fazeres que possibilitem uma educação de qualidade para todos e todas, respeitando a diversidade e a diferença entre as culturas no Brasil.

\section{Referências}

ALVES, Nilda. Cultura e cotidiano escolar. In: Revista Brasileira de Educação, Campinas, ANPEd, Autores Associadas, $\mathrm{n}^{\mathrm{o}}$ 23, p. 62-74, maio/ago. 2003. Disponível em: http://www.scielo.br/pdf/rbedu/n23/n23a04.pdf. Acesso em: abril 2014.

ARFUCH, Leonor. O espaço biográfico: dilemas da subjetividade contemporânea. Trad. Paloma Vidal. - Rio de Janeiro: EDUERJ, 2010.

BATISTA NETO, José. Algumas considerações teóricas e metodológicas sobre a abordagem biográfica, instrumento da pesquisa educacional e da formação: contribuições da Escola de 
Chicago e do interacionismo simbólico. In.: Encontro de Pesquisa Educacional do Norte e Nordeste. $18^{\circ}$, 2007, Maceió, Anais... Macieó, EDUFAL, p. 1-18.

BAUMAN. Zigmund. Sociedade individualizada: vidas contadas e histórias vividas. Tradução José Gradel. - Rio de Janeiro: Zahar, 2008.

BENJAMIN, Walter. Magia e técnica, arte e política: ensaios sobre literatura e história da cultura; tradução Sérgio Paulo Rouanet. Obras escolhidas - Vol.1 - $8^{\mathrm{a}}$ Ed. Revista - São Paulo: Brasiliense, 2012.

BERTAUX, Daniel. Narrativas de vida: a pesquisa e seus métodos. Trad. Zuleide Alves Cardoso Cavalcante, Denise Maria G. Lavallé. Natal, RN: EDUFRN, São Paulo. Paulus, 2010.

BOHNSACK, R.; WELLER, W. O método documentário na análise de grupos de discussão. In: WELLER, W.; PFAFF, Nicole. (Org.). Metodologia da pesquisa qualitativa em educação. 2. Ed. - Petrópolis, RJ: Vozes, 2011, p. 67-86.

CAVALLEIRO, Eliane Santos. Considerações sobre etnografia na escola e prática de investigação sobre as relações raciais e de gênero. In: WELLER, W.; PFAFF, N. (Org.). Metodologia da pesquisa qualitativa em educação. 2. ed. - Petrópolis, RJ: Vozes, 2011, p. 271288.

CERTEAU, Michel de. A invenção do cotidiano: 1. Arte de fazer. 18. ed. Tradução de Efphraim F. Alves. Petrópolis, RJ: Vozes, 2012.

CROODS, Os. Direção: Kirk De Micco; Chris Sanders. Produção:Kristine Belson, Jane Hartwell. 1 DVD (99 min), NTSC, color. Gênero Animação. EUA, 2013. Distribuidora: Fox Filme do Brasil. Título original: The Croods.

CUNHA, Jorge Luiz da. Pesquisa com (auto)biografias: interfaces em tempos de individualização. In: ABRAHÃO, Maria Helena Menna; PASSEGI, Maria da Conceição. (Org.). Dimensões epistemológicas e metodológicas da pesquisa (auto)biográfica: Tomo I. Natal: EDUFRN; Porto Alegre: EDIPUCRS; Salvador: EDUNEB, 2012, p. 95-113.

DELORY-MOMBERGER, Christine. Biografia e educação: figuras do indivíduo-projeto; tradução de Maria da Conceição Passegi, João Gomes da Silva Neto e Luis Passegi. - Natal, RN: EDUFRN; São Paulo: Paulus, 2008.

. A pesquisa biográfica: projeto epistemológico e perspectiva metodológica. Tradução de Albino Pozzer. In: ABRAHÃO, Maria Helena Menna Barreto. PASSEGI, Maria da Conceição. (Org.). Dimensões epistemológicas e metodológicas da pesquisa (auto)biográfica: Tomo I. Natal: EDUFRN; Porto Alegre: EDIPUCRS; Salvador: EDUNEB, 2012, p. 71-94.

FERRAROTI, Franco. Sobre a autonomia do método bográfico. In: NÓVOA, António.; FINGER, Matthias. O método (auto)biográfico e a formação. Natal, RN EDUFRN; São Paulo: Paulus, 2010, p. 31-57.

FINGER, Matthias. O método (auto)biográfico e a formação. . In: NÓVOA, António.; FINGER, Matthias. O método (auto)biográfico e a formação. Natal, RN EDUFRN; São Paulo: Paulus, 2010, p. 19-29. 
FURLANETTO, E. C. Os caminhos de construção de uma pesquisa simbólica. In: SOUZA, Elizeu Clementino de. PASSEGGI, Maria da Conceição. (Org.). Pesquisa (auto)biográfica: cotidiano, imaginário e memória. Natal, RN, São Paulo, 2008, p. 91-111.

GADAMER, H-G. Verdade e Método. Rio de Janeiro: Vozes. Editora Unisinos, 1996.

GALEFFI, Dante. O rigor nas pesquisas: uma abordagem fenomenológica em chave transdisciplinar. In: MACEDO, Roberto Sidnei. Um rigor outro sobre a qualidade na pesquisa qualitativa: educação e ciência humana. Salvador: EDUFBA, 2009, p. 13-74.

GEIMER, Alexander. Práticas culturais de recepção e apropriação de filmes na perspectiva da Sociologia Praxeológica do Conhecimento. In: WELLER, W.; PFAFF, N. Metodologias da pesquisa qualitativa em educação. 2. Ed., Petrópolis, Rj: Vozes, 2011. p. 135-150.

GOSS, K. P. Trajetórias militantes: análise de entrevistas narrativas com professores e integrantes do movimento negro. In: WELLER, W.; PFAFF, N.; (Org.). Metodologia da pesquisa qualitativa em educação. 2. ed. - Petrópolis, RJ: Vozes, 2011, p. 223-238.

JOVCHELOVITCH, S.; BAUER, M. Entrevista narrativa. In: BAUER, Martin W.; GASKEEL, George (Orgs.). Pesquisa qualitativa com texto: imagem e som: um manual prático. Tradução Pedrinho A. Guareschi. Petrópolis: Vozes, 2002, p. 90-113.

MACEDO, Roberto Sidnei. Atos de currículo formação em ato? para compreender, entender e problematizar o currículo e formação. Ilhéus: Editus, 2009.

Brasília: Líber Livro Editora, 2007.

Etnopesquisa crítica/etnopesquisa-formação. Série Pesquisa,

MELO NETO, João Cabral de. Poemas. In: MACHADO, L. R. Novas Seletas. Rio de Janeiro: Nova Fronteira, 2002, p.13, 23, 29.

MOTEAGUDO, J. González. As histórias de vida em educação: entre a formação, pesquisa e testemunho. In: SOUZA, Elizeu Clementino de. (Org.). Memória, (Auto)biografia e diversidade: questões de método e trabalho docente. Salvador: EDUFBA, 2011, p. 135-148.

NÓVOA, António. A formação tem que passar por aqui: as histórias de vida do Projeto Prosalus. In. NÓVOA, A.; FINGER, M. (Org.). O método (auto)biográfico e a formação. - Natal: EDUFRN, São Paulo: Paulus, 2010, p. 155-187.

OLIVEIRA, I. B. de. Estudos do cotidiano e pesquisa em educação: Interfaces com as narrativas autobiográficas na compreensão do potencial emancipatório das práticas educativas cotidianas. In: SOUZA, E. C. de.; PASSEGGI, M. da C. (Org.). Pesquisa (auto)biográfica: cotidiano, imaginário e memória. Natal, RN, São Paulo, 2008, p. 163-182.

PINEAU, G.; LE GRAND, Jean-Louis. As histórias de vida. Trad. Carlos Eduardo Galvão Braga e Maria da Conceição Passeggi. Natal, RN: EDUFRN, 2012.

SOUZA, E. C. de. A arte de contar e trocar experiências: reflexões teórico-metodológicas sobre história de vida em formação. In. Revista Educação em Questão, Natal, v. 25, n. 11, p. 22-39, jan./abr. 2006.

Diálogos cruzados sobre pesquisa (auto)biográfica: análise compreensivainterpretativa e política de sentido. In: Revista do Centro em Educação UFSM, Santa Maria, Rio Grande do Sul, v. 39, n. 1, p. 39-50, jan./abr. 2014. 
WELLER, W. Grupos de discussão: aportes teóricos e metodológicos. In: WELLER, W.; PFAFF, N. (Org.). Metodologia da pesquisa qualitativa em educação. 2. ed. - Petrópolis, RJ: Vozes, 2011, p. 55-66.

i Pesquisador 1D CNPq. Professor Titular do Programa de Pós-Graduação em Educação e Contemporaneidade, da Universidade do Estado da Bahia (PPGEduC-UNEB). Coordenador do GRAFHO (Grupo de Pesquisa (Auto)biografia, Formação e História Oral). Pesquisador associado do Laboratorie EXPERICE (Université de Paris 13- Paris 8). Tesoureiro da Associação Brasileira de Pesquisa (Auto)biográfica (BIOgraph) e Diretor Financeiro da ANPEd (2013-2015). Membro do Conselho de Administração da Association Internationale des Histories de Vie en Formation et de La Recherche Biographique en Education (ASIHIVIF-RBE). Coordenador do Projeto: "Multisseriação e trabalho docente: diferenças, cotidiano escolar e ritos de passagem" (CNPq e FAPESB). E-mail: esclementino@uol.com.br

ii Mestre e doutoranda em Educação e Contemporaneidade, pelo Programa de Pós-graduação em Educação e Contemporaneidade da Universidade do Estado da Bahia (PPGEduC/ UNEB). Membro do Grupo de Pesquisa (Auto)biografia, Formação e História Oral (GRAFHO). Professora de Orientação e Mobilidade para pessoas com deficiência Visual - SEC/BA. Coordenadora Pedagógica de Escola em Território Rural, da Prefeitura Municipal de Feira de Santana- Bahia. E-mail: rcmagal@yahoo.com.br

iii Dialogamos com questões teórico-metodológicas do/nos/com os cotidianos em um processo de vizinhanças e aproximações com as pesquisas em educação sobre cotidiano escolar, desenvolvidas por Alves (2003) e Oliveira (2008).

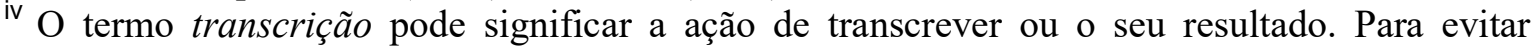
confusões, designamos aqui (por convenção) a ação de transcrever como retranscrever $e$ retranscrição, reservando o termo transcrição ao texto resultante (grifo do autor). (BERTAUX, 2010, p. 90).

${ }^{\vee} \mathrm{O}$ filme foi exibido com o grupo constituído com 11 alunos(as), do total de 14 participantes. 